\title{
Sorption characteristics and mechanisms of ammonium by coal by-products: slag, honeycomb-cinder and coal gangue
}

\author{
L. Y. Zhang $\cdot$ H. Y. Zhang • \\ W. Guo $\cdot$ Y. L. Tian
}

Received: 5 December 2011/Revised: 16 October 2012/Accepted: 23 December 2012/Published online: 13 February 2013

(C) Islamic Azad University (IAU) 2013

\begin{abstract}
The adsorption behaviors of ammonium from aqueous solutions were investigated for three solid coal wastes, slag, honeycomb-cinder and coal gangue. The ammonium sorption processes were well modeled by the pseudo second-order model $\left(R^{2}>0.99\right)$. The experimental data were fitted to both the Langmuir model and the Freundlich model, with the Langmuir model better representing the data. The maximum ammonium sorption capacities calculated from the Langmuir model were 3.1, 5.0 and $6.0 \mathrm{mg} / \mathrm{g}$ for the slag, honeycomb-cinder and coal gangue samples, respectively. The $\mathrm{pH}$ value of the solution affected the ammonium removal, and the higher uptakes found in either neutral or alkaline conditions for the three materials. The thermodynamic parameters, $\Delta H$, were calculated to be 29.75, 25.21 and $17.91 \mathrm{~kJ} / \mathrm{mol}$ for the SL, HC and CG samples, respectively, with the positive values indicating that the ammonium sorption processes were endothermic. Based on the results, it can be concluded that coal gangue may have more potential for being used as a sorbent for the ammonium removal from wastewater among the three coal by-products.
\end{abstract}

\footnotetext{
L. Y. Zhang · H. Y. Zhang $(\bowtie) \cdot$ W. Guo - Y. L. Tian Research Center for Ecological Engineering and Nonlinear Science, North China Electric Power University, Beijing 102206, China

Keywords Ammonium - Coal gangue . Honeycomb-cinder $\cdot$ Slag $\cdot$ Sorption

\section{Introduction}

As a structural component of amino acids, proteins and genetic materials, nitrogen compounds are essential elements for living organisms (McVeigh 1999; Dachs et al. 2000). With the rapid societal and economic development throughout the world, increased levels of nitrogen being released into water supplies can lead the eutrophication in lakes and rivers, resulting in the depletion of dissolved oxygen and the toxicity for fish, even the destruction of aquatic ecologies (Du et al. 2005; Maraňón et al. 2006; Sondergaard and Jeppesen 2007). Ammonia and ammonium ions are the more commonly encountered nitrogenous compounds in wastewater, and only $0.2 \mathrm{mg} / \mathrm{L}$ may be toxic to fish and other forms of aquatic life (Haralambous et al. 1992). Biological methods relative to the denitrification/ nitrification are commonly used to remove ammonium from wastewater (de-Bashan et al. 2004; Joo et al. 2007). However, these processes have their own limitations, such as a lack of an ability to respond to shock loading of ammonium with the requirements of a constant $\mathrm{C} / \mathrm{N}$ ratio to ensure the survival of the microorganisms used in these processes (Karadag et al. 2006; Yang et al. 2007) and an unstable effectiveness under seasonal conditions (Kurama et al. 2010). Other physical/chemistry methods have also been used to treat wastewater containing ammonium (Ben Ali et al. 2004; Kurama et al. 2010; Coetzee et al. 2011; Uğurlu and Karaoğlu 2011). Among these methods, adsorption or ion exchange has become an important treatment method due to the ease of operation and the economic feasibility of this approach (Karadag et al. 2006; 
Saltalı et al. 2007). The key issue of adsorption method is to find both effective and low-cost adsorbents, such as zeolite (Wu et al. 2006; Lei et al. 2008).

Coal is the main energy source in multiple countries, especially in developing countries. In coal mining and utilization, the solid waste produced, such as coal gangue (CG), slag (SL) and honeycomb-cinder (HC), can not only occupy significant quantities of land, but also pollute the environment (Bell and Stacey 2000; McKinnon 2002). Coal gangue, a complex of sandy shale and clay, is produced during coal mining and washing. Slag and honeycomb-cinder are two types of solid wastes produced from both cooking and heating in most towns in China. According to statistics, the annual emission of coal gangue in China is approximately $1.5-2.0 \times 10^{8}$ tons (Wang et al. 2009), and the production of the other wastes is approximately 400 million tons every year (Lee et al. 2010). The reuse of these coal by-products has been investigated for use in producing cement and in power generation, while the utilization rate is still lower than $15 \%$ (Shi et al. 2005; $\mathrm{Li}$ et al. 2006). In recent years, new disposal or utilization methods of these solid wastes have been investigated for use, such as being an absorbent, because these materials have a relatively high surface area as well as hydrous metal oxides (Gong et al. 2007; Wang et al. 2010). Several studies have focused on the removal of phosphate, heavy metals and dyes using coal gangue and slag (O Ŏuz 2004; Qin et al. 2007; Nehrenheim and Gustafsson 2008; Xue et al. 2009; Wang et al. 2010) and the sorption of phosphate, aniline and nitrobenzene naphthalene from wastewater using honeycomb-cinder (Hao 2003; Lee et al. 2010). However, a complete characterization of the ammonium removal by these coal by-products has not yet been reported.

The aim of this study was to determine the sorption capacity of slag, honeycomb-cinder and coal gangue for the ammonium removal from wastewater. The sorption isotherm kinetics were studied to analyze the ammonium sorption process by these materials. The effects of $\mathrm{pH}$, initial concentration and temperature were also investigated to find the favorable processing conditions.

\section{Materials and methods}

Materials and characterization

The slag and honeycomb-cinder used in the experiments were obtained from the boiler room of the North China Electric Power University. The coal gangue was obtained from Chifeng City (Inner Mongolia, China). All samples were dried overnight in an air-drying oven at $100{ }^{\circ} \mathrm{C}$ to obtain a constant weight and ground through a size of 100 mesh.

The $\mathrm{pH}$ values and the electric conductivity (EC) of the samples were determined in a slurry of adsorbent/distilled water (1:2.5 ratio). The compositions of the materials were determined using a Philips PW2404 X-ray fluorescence spectrometer (XRF), according to the method China GB/ T14506.28-93. The specific surface area was determined by fitting the amount of $\mathrm{N}_{2}$ adsorbed at $-196{ }^{\circ} \mathrm{C}$ to the Brumauer-Emmett-Teller (BET) equation after a preliminary heating to $200{ }^{\circ} \mathrm{C}$ (Quadrasorb SI, Quantachrome). The mineralogical phases were determined using $\mathrm{X}$-ray diffraction (XRD) equipment (Rikaku D/max-RB, Rikaku). FT-IR spectra using the $\mathrm{KBr}$ pressed disk technique on a NICOLET 750 FT-IR spectrophotometer were measured for the spectra range of $4,000-400 \mathrm{~cm}^{-1}$.

\section{Sorption studies}

All glass bottles were soaked in $10 \%$ diluted $\mathrm{HCl}$ solution for $12 \mathrm{~h}$ and washed three times with distilled water. An original stock solution containing $1000 \mathrm{mg} / \mathrm{L}$ ammonium was prepared by dissolving $3.8214 \mathrm{~g}$ of $\mathrm{NH}_{4} \mathrm{Cl}$ in $1,000 \mathrm{~mL}$ of distilled water. The working solutions were prepared by diluting the original stock solution with distilled water. The $\mathrm{pH}$ values of the solutions were adjusted by $1.0 \mathrm{~mol} / \mathrm{L} \mathrm{HCl}$ or $1.0 \mathrm{~mol} / \mathrm{L} \mathrm{NaOH}$ solution and monitored using a $\mathrm{pH}$ meter (LIDA DDS-11A). Each experiment was performed in triplicate to ensure reproducibility. The average values were used in the analysis.

\section{Kinetic experiments}

Before the start of each kinetic experiment, $0.5 \mathrm{~g}$ of each sample with $50 \mathrm{ml}$ ammonium solution $(10,60$ and $100 \mathrm{mg} / \mathrm{L}$ ) was placed into a series of $250-\mathrm{mL}$ stoppered conical flasks. The flasks were shaken at $180 \mathrm{rpm}$ in a thermostatic shaker bath at $25{ }^{\circ} \mathrm{C}$. At the different time intervals $(5,10,20,30,45,60,90,120,180,300 \mathrm{~min})$, these suspensions were centrifuged at 4,000 rpm for $5 \mathrm{~min}$ and filtered through a $0.45-\mu \mathrm{m}$ membrane.

\section{Equilibrium experiments}

A series of suspensions, each containing $0.5 \mathrm{~g}$ adsorbent and $50 \mathrm{~mL}$ of the ammonium solutions, were prepared. The initial ammonium concentrations ranged from 10 to $300 \mathrm{mg} / \mathrm{L}(10,20,40,60,100,150,200,300 \mathrm{mg} / \mathrm{L})$. To reach equilibrium conditions, the mixtures were shaken for $2.5 \mathrm{~h}$ in a thermostatic shaker at $25^{\circ} \mathrm{C}$. After shaking, the suspensions were centrifuged and the supernatants were analyzed for the concentrations of ammonium residue. 
The effects of $\mathrm{pH}$ and temperature

The influence of the initial ammonium solution $\mathrm{pH}$ values was observed at $\mathrm{pH}$ values ranging between 2.0 and 12.0. The initial ammonium concentration and the dosage of the adsorbents were $60 \mathrm{mg} / \mathrm{L}$ and $0.5 \mathrm{~g}$, respectively. The effect of temperature was studied at 25,35 and $45^{\circ} \mathrm{C}$. The initial $\mathrm{pH}$ values were adjusted to 9.0 for SL and $\mathrm{HC}$, and 10.0 for CG.

\section{Analytical methods}

The concentration of ammonium was measured using the Nesslerization method with a Shimadzu UV-2550 UV-Vis spectrophotometer at $420 \mathrm{~nm}$. The adsorption capacity and the ammonium removal efficiency were calculated by Eqs. 1 and 2 .

$q_{\mathrm{e}}=\frac{C_{0}-C_{\mathrm{e}}}{m} \times V$

$\%=\frac{C_{0}-C_{\mathrm{e}}}{C_{0}} \times 100 \%$,

where $q_{\mathrm{e}}$ is the ammonium adsorbed on the sorbents (mg/g), $C_{0}$ and $C_{\mathrm{e}}$ are the initial and the equilibrium ammonium concentrations in the test solution $(\mathrm{mg} / \mathrm{L})$, respectively, $V$ is the test solution volume (L) and $m$ is the amount of sorbent that was used (g).

\section{Results and discussion}

\section{Characterization of the materials}

The chemical compositions of the slag, the honeycombcinder and the coal gangue were determined by XRF, as shown in Table $1 . \mathrm{SiO}_{2}$ was the main composition in the three materials, consisting of $60.82,51.48$ and $43.39 \%$ for the SL, HC and CG samples, respectively. The $\mathrm{Al}_{2} \mathrm{O}_{3}$ content in the samples was determined to be 18.30, 25.96 and $13.72 \%$ for the SL, HC and CG samples, respectively. The value of the loss on ignition was $29.1 \%$ for the CG sample. This value was not only larger than our measured values for $\mathrm{SL}$ and $\mathrm{HC}$, but also larger than the values reported for other materials, such as $0.24 \%$ of natural zeolite (Sprynskyy et al. 2005) and $3.9 \%$ for blast furnace slag (Oğuz 2004). The surface area of the CG $\left(12.63 \mathrm{~m}^{2} / \mathrm{g}\right.$ ) was significantly higher than the values of the SL $\left(4.02 \mathrm{~m}^{2} /\right.$ g) and the $\mathrm{HC}\left(2.13 \mathrm{~m}^{2} / \mathrm{g}\right)$. The $\mathrm{pH}$ values of the three materials indicated that the SL and the $\mathrm{HC}$ were alkaline materials, while the CG was a neutral material (Table 1).

The crystalline phases of the sorbents determined by XRD analysis are shown in Fig. 1a. The principal crystalline phases were similar in both SL and HC, including quartz, albite and mullite. The over $30 \%$ clay minerals
Table 1 Properties and compositions of the adsorbents

\begin{tabular}{lccc}
\hline Item & $\mathrm{SL}$ & $\mathrm{HC}$ & $\mathrm{CG}$ \\
\hline $\mathrm{SiO}_{2}(\%)$ & 60.82 & 51.48 & 43.39 \\
$\mathrm{Al}_{2} \mathrm{O}_{3}(\%)$ & 18.30 & 25.96 & 13.72 \\
$\mathrm{Fe}_{2} \mathrm{O}_{3}(\%)$ & 5.95 & 4.73 & 6.09 \\
$\mathrm{CaO}(\%)$ & 6.35 & 8.84 & 1.70 \\
$\mathrm{MgO}(\%)$ & 0.99 & 1.29 & 1.60 \\
$\mathrm{Na}_{2} \mathrm{O}(\%)$ & 1.10 & 1.49 & 0.56 \\
$\mathrm{~K}_{2} \mathrm{O}(\%)$ & 2.16 & 1.67 & 2.05 \\
$\mathrm{MnO}(\%)$ & 0.085 & 0.080 & 0.047 \\
$\mathrm{TiO}_{2}(\%)$ & 0.83 & 1.01 & 0.89 \\
$\mathrm{P}_{2} \mathrm{O}_{5}(\%)$ & 0.15 & 0.54 & 0.12 \\
$\mathrm{Loss}$ on ignition $(\%)$ & 3.02 & 2.66 & 29.81 \\
$\mathrm{~S}_{\mathrm{BET}}\left(\mathrm{m}^{2} / \mathrm{g}\right)$ & 4.02 & 2.13 & 12.63 \\
$\mathrm{pH}$ & 10.8 & 12.3 & $\mathbf{6 . 6}$ \\
$\mathrm{EC}(\mathrm{mS} / \mathrm{cm})$ & 0.93 & 2.91 & $\mathbf{1 . 1 3}$ \\
\hline
\end{tabular}

$S L$ slag, $H C$ honeycomb-cinder, $C G$ coal gangue, $S_{B E T}$ specific surface area, $E C$ electric conductivity

present in the CG, such as kaolinite, chlorite and illite, might improve the sorption ability of the CG, as these clay minerals have been reported to have high cation exchange and swelling capacities (Xi et al. 2010).

The FT-IR spectra of the SL, HC and CG samples are shown in Fig. 1b. For all sample spectra, several distinct and sharp absorption bands as well as relatively low intensity peaks were observed. The bands between 3,200 and $3,600 \mathrm{~cm}^{-1}$ correspond to the $\mathrm{O}-\mathrm{H}$ and the $\mathrm{N}-\mathrm{H}$ stretching vibrations of the hydroxyl and the amino groups that are attached to the octahedral $\mathrm{Al}$ ions located in the interior blocks of the samples. The stretching vibrations of either $\mathrm{Si}-\mathrm{O}-\mathrm{Si}$ or $\mathrm{Si}_{-} \mathrm{O}^{-}$appeared in the range of $900-1,200 \mathrm{~cm}^{-1}$. The bands in the range of $400-500 \mathrm{~cm}^{-1}$ indicated either $\mathrm{O}-\mathrm{Si}-\mathrm{O}$ or $\mathrm{O}-\mathrm{Si}-\mathrm{O}^{-}$bending vibrations. The transmittance peaks at 680,720 and $800 \mathrm{~cm}^{-1}$ are due to the bands of the $\mathrm{TO}_{4}\left(\mathrm{~T}: \mathrm{Al}^{3+}, \mathrm{Fe}^{3+}, \mathrm{Si}^{4+}\right)$ groups in the three materials. The band at $1,623 \mathrm{~cm}^{-1}$ was observed in the coal gangue corresponding to the $\mathrm{OH}$ deformation of water. The transmittance peaks related to the $\mathrm{Al}-\mathrm{O}-\mathrm{Si}$ and the $\mathrm{Al}-\mathrm{OH}$ groups also appeared in the FT-IR patterns of the coal gangue in bands at 535 and $910 \mathrm{~cm}^{-1}$, respectively.

\section{Kinetics studies}

Kinetic studies are vital for any sorption process to predict the solute uptake rate of the sorbents and to provide essential information on the reaction pathways. To analyze the kinetic processes of the ammonium sorption onto the materials, three kinetic models, pseudo first-order model (Dizadji and Abootalebi Anaraki 2011), pseudo second- 

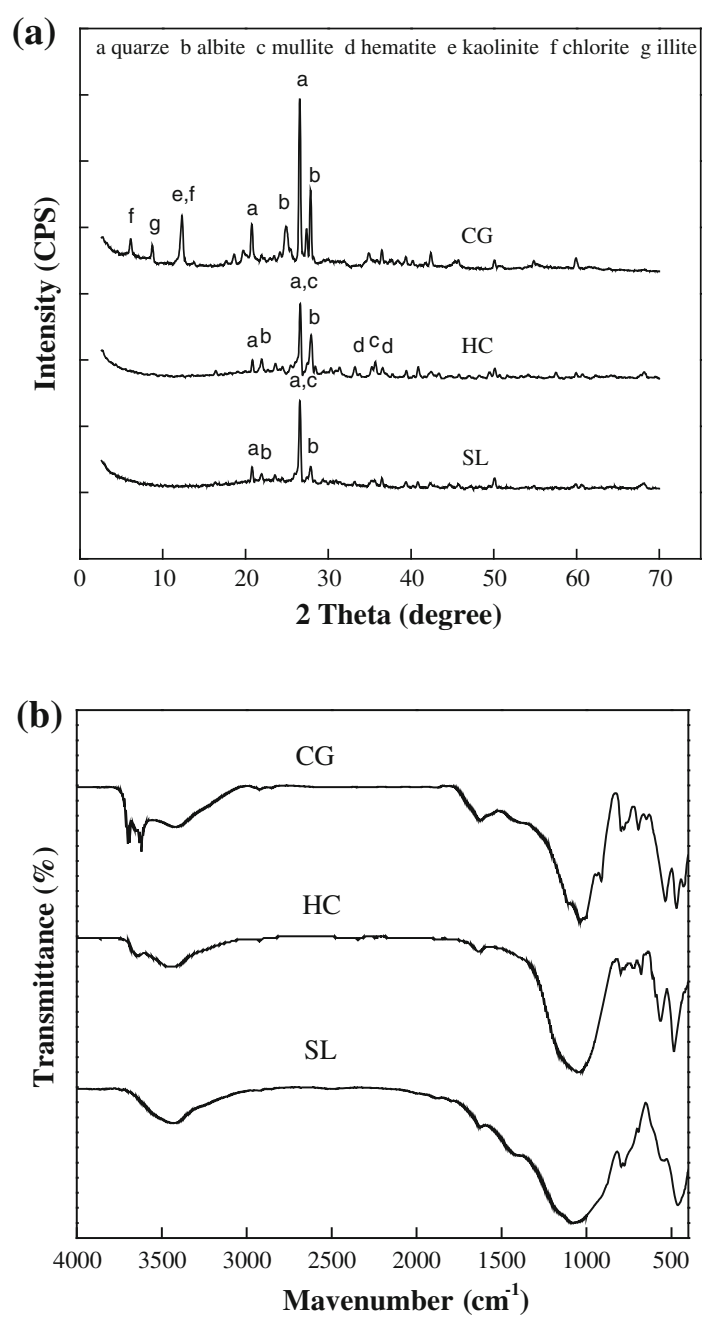

Fig. 1 The characteristics of the materials: a mineralogical phases; b the FT-IR spectra

order model (Ho and Mckay 1999) and intra-particle diffusion model (Weber and Morris 1963), were used to test the experiment data.

The pseudo first-order model is presented by Eq. 3 .

$\ln \left(q_{\mathrm{e}}-q_{t}\right)=\ln q_{\mathrm{e}}-k_{1} t$,

where $q_{\mathrm{e}}$ and $q_{t}$ are the amount of the ammonium adsorbed on the sorbent $(\mathrm{mg} / \mathrm{g})$ at equilibrium and at time $t$, respectively, and $k_{1}$ is the constant of the pseudo first-order sorption $(\mathrm{L} / \mathrm{min})$.

The pseudo second-order model based on the sorption equilibrium capacity may be expressed as Eq. 4 .

$\frac{t}{q_{t}}=\frac{1}{k_{2} q_{\mathrm{e}}^{2}}+\frac{t}{q_{\mathrm{e}}}$.

The initial sorption rate, $h,(\mathrm{mg} / \mathrm{g} \cdot \mathrm{min})$ is expressed as

$h=k_{2} q_{\mathrm{e}}^{2}$,

where $q_{\mathrm{e}}$ and $q_{t}$ are the same meaning with the pseudo firstorder model and $k_{2}$ is the sorption rate constant of this model (g/mg $\cdot \mathrm{min})$. The constants $h$ and $q_{\mathrm{e}}$ are calculated from the intercept and the slope of the line obtained by plotting $t / q_{t}$ versus $t$. These values are listed in Table 2 .

The intra-particle diffusion rate parameter expressed in terms of the square root of time and the sorption capacity can be determined from Eq. 6 .

$q_{t}=k_{\mathrm{d}} t^{0.5}+C$,

where $k_{\mathrm{d}}$ is the intraparticle diffusion rate constant $\left(\mathrm{mg} / \mathrm{g} \cdot \mathrm{min}^{1 / 2}\right)$ and $C$ is a constant that relates to the thickness of the boundary layer $(\mathrm{mg} / \mathrm{g})$.

Figure 2 showed the kinetic curves of the ammonium sorption by the three materials at different initial concentrations in aqueous solutions (10, 60 and $100 \mathrm{mg} / \mathrm{L})$. In the first $30 \mathrm{~min}$, over $80 \%$ of the ammonium ions were removed by the materials. After this fast initial sorption step, the ammonium uptake rate increased slowly with time, and no significant changes observed after $120 \mathrm{~min}$. When the contact times were greater than $2 \mathrm{~h}$, no significant changes were observed, indicating that the sorption was in a state of dynamic equilibrium between the ammonium desorption and the sorption on the sorbents. The first rapid sorption process may be a result of the vacant of all sorbent sites and the high concentration gradient between the solution and the sorbent (Onundi et al. 2010). With increasing contact time, the available adsorbed sites on the sorbent surface was diminished and the the solute concentration was decreased, leading the rate of sorption to become slower as the process approached equilibrium. The CG removed higher quantities of ammonium than the other materials, as shown in Fig. 2. This could be attributed to the large surface area and the high content of organic matter in the CG (Liu and Lee 2007). In addition, the $\mathrm{OH}^{-}$on the surface of the SL and the HC reacted quickly with the $\mathrm{NH}_{4}{ }^{+}$in the solution, obstructing the further exchange between the cation on the sorbent surface and the $\mathrm{NH}_{4}{ }^{+}$, which did not occur on the CG due to the acidity of the material (Rožić et al. 2000).

According to the equation of the pseudo first-order model, the plots of $\ln \left(q_{\mathrm{e}}-q_{t}\right)$ versus $t$ should give linear relationship with a slope of $k_{1}$ and an intercept of $\ln \left(q_{\mathrm{e}}\right)$. Although the correlation coefficients of the pseudo firstorder model for the three sorbents were high $(>0.96)$, the values of $q_{\mathrm{e}}$ obtained from this equation were not in agreement with the experimental data (Table 2), which indicated that this pseudo first-order kinetic did not fit the process of the ammonium sorption on the sorbents. In fact, the pseudo first-order kinetic equation differed from a true first-order equation for two reasons: the parameter $q_{\mathrm{e}}-q_{t}$ did not include all the available sites and the parameter $\ln \left(q_{\mathrm{e}}\right)$ did not equal the intercept of the plots of $\ln \left(q_{\mathrm{e}}-q_{t}\right)$ versus $t$. In a true first-order model, this parameter should 
Table 2 The kinetic model constants for the ammonium adsorption on the adsorbents

\begin{tabular}{|c|c|c|c|c|c|c|c|c|c|}
\hline \multirow[t]{2}{*}{ Ammonium concentration $(\mathrm{mg} / \mathrm{L})$} & \multicolumn{3}{|l|}{ SL } & \multicolumn{3}{|l|}{$\mathrm{HC}$} & \multicolumn{3}{|l|}{ CG } \\
\hline & 10 & 60 & 100 & 10 & 60 & 100 & 10 & 60 & 100 \\
\hline \multicolumn{10}{|l|}{ Pseudo first-order model } \\
\hline$k_{1}(\mathrm{~L} / \mathrm{min})$ & 0.041 & 0.046 & 0.042 & 0.45 & 0.047 & 0.049 & 0.048 & 0.044 & 0.049 \\
\hline$q_{\mathrm{e}}(\mathrm{mg} / \mathrm{g})$ & 0.089 & 0.204 & 0.520 & 0.133 & 0.600 & 1.126 & 0.141 & 0.592 & 1.677 \\
\hline$R^{2}$ & 0.983 & 0.989 & 0.985 & 0.993 & 0.986 & 0.961 & 0.999 & 0.986 & 0.970 \\
\hline \multicolumn{10}{|l|}{ Pseudo second-order model } \\
\hline$k_{2}(\mathrm{~g} / \mathrm{mg} \cdot \min )$ & 0.675 & 0.349 & 0.136 & 0.360 & 0.121 & 0.029 & 0.554 & 0.203 & 0.039 \\
\hline$q_{\mathrm{e}}(\mathrm{mg} / \mathrm{g})$ & 0.112 & 0.405 & 0.730 & 0.162 & 0.686 & 1.351 & 0.267 & 1.513 & 2.556 \\
\hline$h(\mathrm{mg} / \mathrm{g} \cdot \min )$ & 0.009 & 0.057 & 0.073 & 0.010 & 0.057 & 0.052 & 0.040 & 0.465 & 0.255 \\
\hline$R^{2}$ & 0.999 & 0.999 & 0.999 & 0.999 & 0.999 & 0.999 & 0.999 & 0.999 & 0.999 \\
\hline \multicolumn{10}{|l|}{ Intra-particle diffusion model } \\
\hline$k_{\mathrm{d} 1}\left(\mathrm{mg} / \mathrm{g} \cdot \min ^{1 / 2}\right)$ & 0.017 & 0.070 & 0.058 & 0.024 & 0.104 & 0.174 & 0.031 & 0.174 & 0.232 \\
\hline$k_{\mathrm{d} 2}\left(\mathrm{mg} / \mathrm{g} \cdot \min ^{1 / 2}\right)$ & 0.013 & 0.023 & 0.072 & 0.017 & 0.077 & 0.151 & 0.016 & 0.075 & 0.228 \\
\hline$R^{2}$ & 0.999 & 0.998 & 0.999 & 0.988 & 0.992 & 0.986 & 0.991 & 0.999 & 0.986 \\
\hline
\end{tabular}

Fig. 2 The effect of the contact time on the ammonium removal by the adsorbents
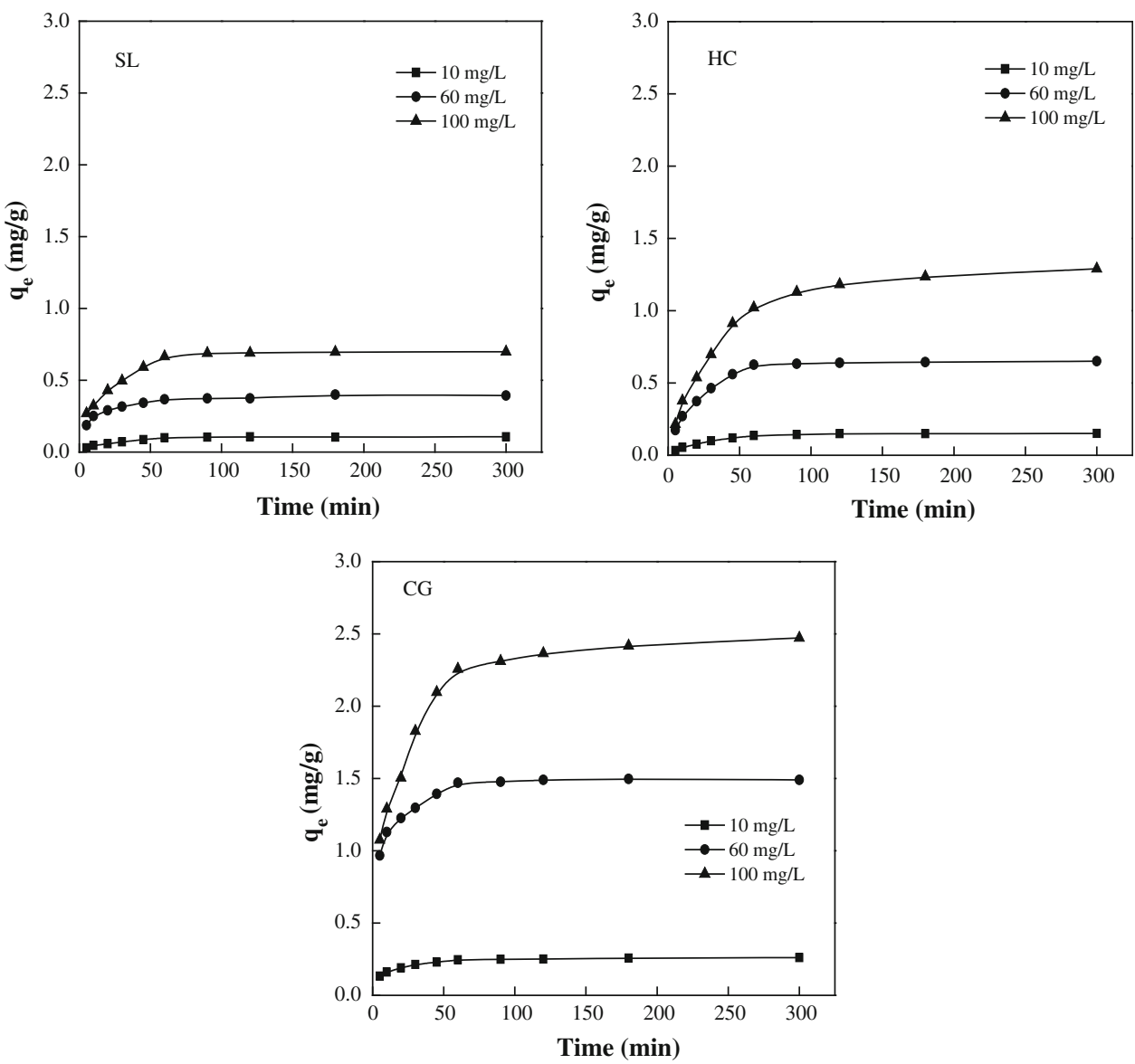

be equal to the intercept (Gupta and Babu 2009). Hence, the pseudo first-order kinetic model was only used for estimating $k_{1}$ alone.

The plots of the pseudo second-order model for a moderate ammonium concentration $(60 \mathrm{mg} / \mathrm{L})$ yielded good straight lines for the different sorbents, as shown in Fig. 3a. The correlation coefficients of the pseudo secondorder model exceeded 0.999 higher than for the values of the pseudo first-order model. In addition, the values of $q_{\mathrm{e}}$ were in good agreement with the experimental values 
(Table 2). The results suggested that the ammonium sorption processes on the three materials fit well with the pseudo second-order model.

As the above models did not explicitly identify the diffusion mechanism during the sorption process, the intraparticle diffusion model was selected to assess this ratelimiting step. It is stated that the intra-particle diffusion could be involved in the sorption process if the plot of $t^{0.5}$ against $q_{t}$ results in a linear relationship, and it would be expected to be the controlling step when this line pass through the origin (Kavitha and Namasivayam 2007). Generally, if the sorption steps are independent of one another, the plot of $q_{t}$ versus $t^{0.5}$ usually demonstrates two or more intercepting lines, depending upon the exact mechanism. According to the previous studies, the sorption mechanism mainly involves: (1) transport in the solution; (2) film diffusion; (3) intra-particle or pore diffusion; and (4) sorption onto the interior sites (Gong et al. 2007). From the plots of the intra-particle diffusion model shown in
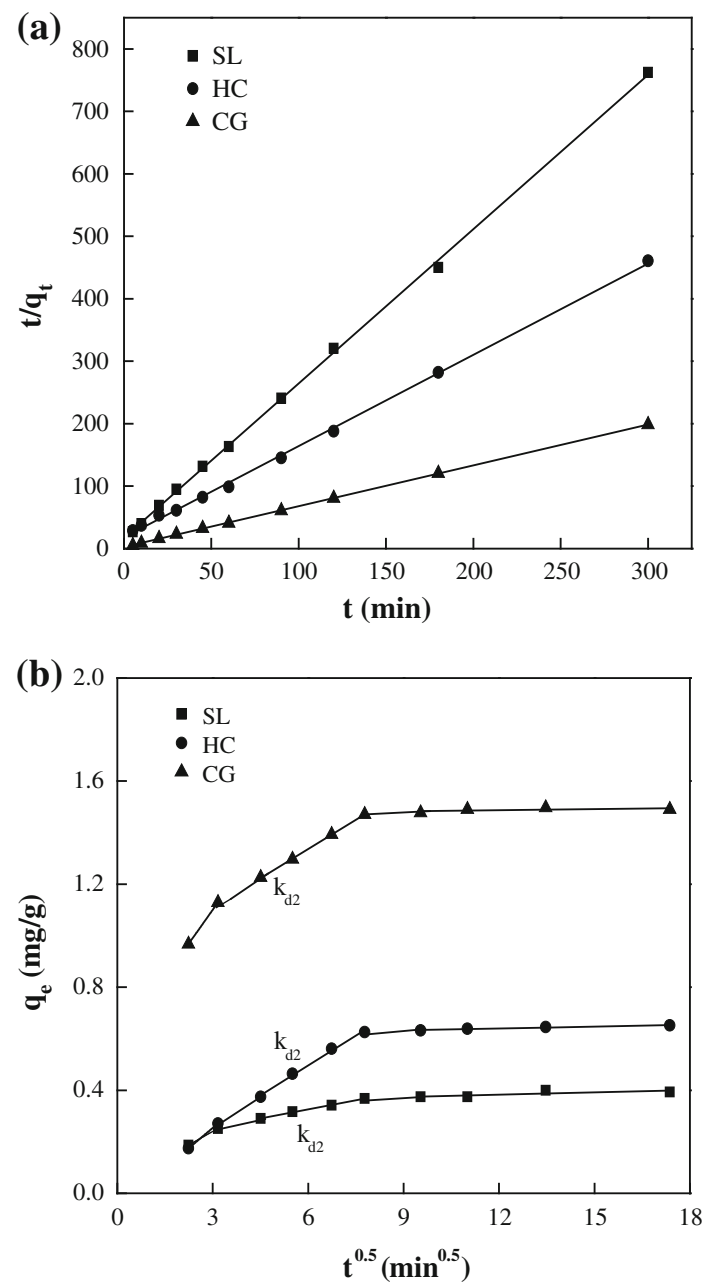

Fig. 3 Kinetics of the ammonium removal on the adsorbents: a pseudo second-order; $\mathbf{b}$ intra-particle diffusion model
Fig. 3b, a multi-linear relationship was observed over the entire time range, suggesting that either two or three different stages were included in the sorption processes (Alkan et al. 2008; Abramian and El-Rassy 2009; Uğurlu and Karaoğlu 2011). The first sorption step was attributed to the diffusion of the adsorbate through the solution to the external surface of the sorbent or the boundary layer diffusion of the solute molecules or ions. The second gradual sorption stage was attributed to the intra-particle diffusion state. The final stage was attributed to an equilibrium state, where intraparticle diffusion started to decrease due to low adsorbate concentrations in the solution and the occupation of the sorbent pores and surfaces, increasing the repulsion for the ammonium sorption (Uğurlu and Karaoğlu 2011). Among these steps, the last step was considered negligible because the adsorption rate was rapid under the sufficient speed of stirring. With these considerations, the intra-particle diffusion state was assumed to be the rate-limiting step of the sorption process as this step was slower than the first film diffusion as indicated by the value of $k_{\mathrm{d}}$ (Ho and McKay 1998). As none of the second linear plots passed through the origin, the intra-particle diffusion was not the only ratelimiting step for the ammonium sorption by the sorbents (Alkan et al. 2008; Abramian and El-Rassy 2009). The sorption kinetic processes of the materials were consistent with the results from the report relating the sorption of ammonium on a microwave-treated natural Chinese zeolite (Lei et al. 2008).

\section{Sorption isotherms}

Sorption isotherms are mathematical models that described the relationship between the concentration of the adsorbate and the amount of adsorbate at a constant temperature. They are mainly related to the heterogeneity/homogeneity of the sorbents, the type of coverage and the possibility of interaction between the adsorbate species. In this study, two isotherm models, the Langmuir and the Freundlich isotherm models, were selected to assess the sorption characteristics and to describe the magnitude of the interactions.

The Langmuir isotherm is the simplest theoretical model for a monolayer sorption onto a surface. This model assumes that all the sorption sites have an equal adsorbate affinity (Bulut and Aydin 2006). This isotherm is applicable for a monomolecular layer sorption, and can be written as:

$q_{\mathrm{e}}=\frac{q_{\mathrm{m}} b C_{\mathrm{e}}}{1+b C_{\mathrm{e}}}$,

where $C_{\mathrm{e}}$ and $q_{\mathrm{e}}$ are the equilibrium concentration $(\mathrm{mg} / \mathrm{L})$ and the adsorbed amount $(\mathrm{mg} / \mathrm{g})$ at equilibrium, respectively, $q_{\mathrm{m}}$ is the Langmuir sorption maximum $(\mathrm{mg} / \mathrm{g})$ and $b$ is the empirical constant of the Langmuir equation. 
The Freundlich isotherm is used for the heterogeneous systems, which assumes that the heat of sorption decreases in magnitude with increasing the extent of sorption (Kavitha and Namasivayam 2007). The Freundlich isotherm is used for heterogeneous systems and can be written as:

$q_{\mathrm{e}}=K_{\mathrm{F}} C_{\mathrm{e}}^{1 / n}$,

where $C_{\mathrm{e}}$ and $q_{\mathrm{e}}$ are the same meaning with the Langmuir model, $K_{\mathrm{F}}$ is the empirical constant of Freundlich equation and $1 / n$ is the heterogeneity factor.

The ammonium sorption capacities of the three materials increased with increasing initial ammonia concentrations (Fig. 4). When the initial ammonium concentration increased to $300 \mathrm{mg} / \mathrm{L}$, the ammonium sorption capacities reached 1.37, 2.28 and $4.06 \mathrm{mg} / \mathrm{g}$ for the SL, HC and CG samples, respectively. The high sorption capacity observed at high initial concentrations may be a result of the increase in the driving forces of the ammonium concentration gradient and an enhancement of the contact probability between the ammonium ions and the material (Jellali et al. 2011). In addition, for initial ammonium concentrations less than $200 \mathrm{mg} / \mathrm{L}$, a linear increase in the uptake capacity by the materials was observed, suggesting that the ammonium concentration had no effect on the sorption mechanism below $200 \mathrm{mg} / \mathrm{L}$ (Hameed and El-Khaiary 2008).

The Langmuir isotherm plots of the ammonium sorption for the SL, HC and CG samples are shown in Fig. 4a. The experimental data were found to fit well to the Langmuir model with high values for the correlation coefficients (Table 3). The maximum sorption capacities $q_{\mathrm{m}}$ calculated from the Langmuir equation were 3.1, 5.0 and $6.0 \mathrm{mg} / \mathrm{g}$ for the SL, HC and CG samples, respectively (Table 3). The Langmuir constants, $b$, were found to be $3.0 \times 10^{-3}$ (SL), $3.3 \times 10^{-3}(\mathrm{HC})$ and $8.3 \times 10^{-3} \mathrm{~L} / \mathrm{mg}(\mathrm{CG})$. The low values of $b$ indicated a high affinity between the ammonium and the sorbents.

An essential feature of the Langmuir equation is the dimensionless separation factor, $R_{\mathrm{L}}$, given by the following equation:

$R_{\mathrm{L}}=\frac{1}{1+b C_{0}}$.

For $0<R_{\mathrm{L}}<1$, a favorable sorption is established. For $R_{\mathrm{L}}>1$, an unfavorable sorption is established. For $R_{\mathrm{L}}=1$, the linear sorption is established. For $R_{\mathrm{L}}=0$, the sorption operation is considered to be irreversible. For initial ammonium concentrations of $10-300 \mathrm{mg} / \mathrm{L}$, the calculated $R_{\mathrm{L}}$ values were found to be in the range of $0.97-0.51,0.98-0.58$ and $0.94-0.34$ for the SL, HC and CG samples, respectively, suggesting that all three sorbents were favorable for the ammonium sorption.
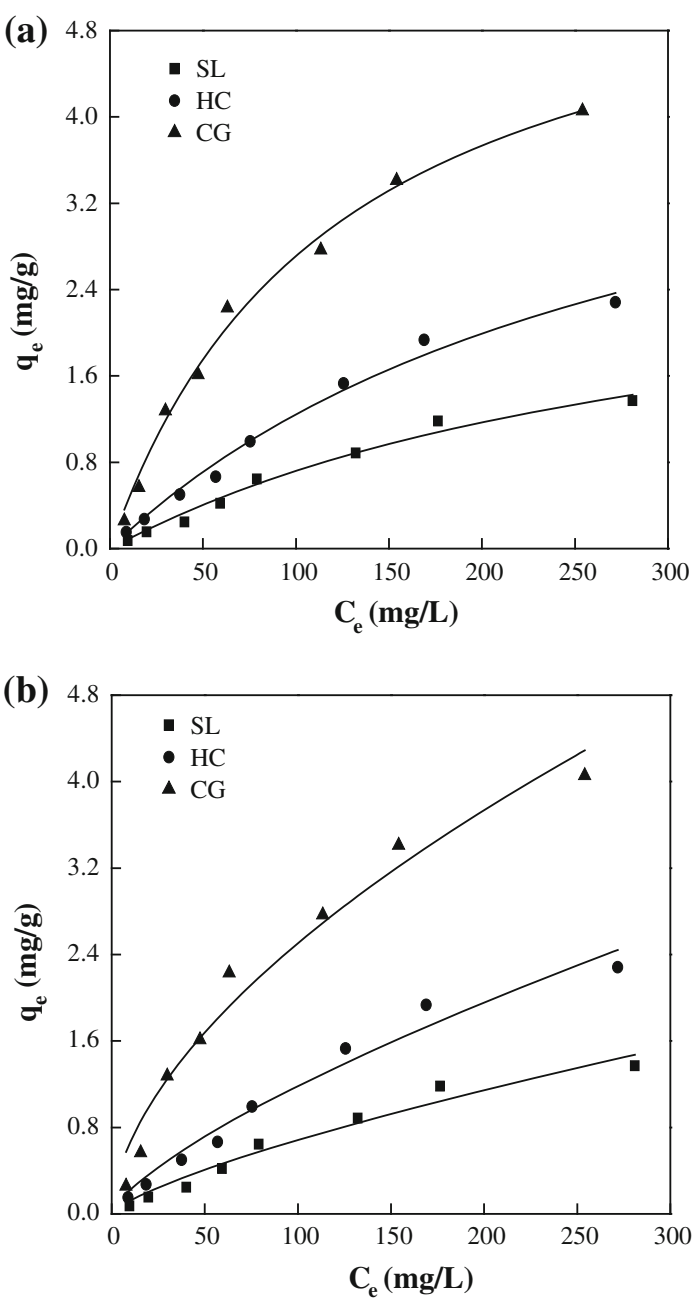

Fig. 4 The plots for the isotherm models: a Langmuir isotherm; b Freundlich isotherm

Table 3 Langmuir and Freundlich constants for the ammonium adsorption on the adsorbents

\begin{tabular}{lllllllll}
\hline Adsorbents & \multicolumn{2}{l}{ Langmuir } & & \multicolumn{4}{l}{ Freundlich } \\
\cline { 2 - 3 } & $\begin{array}{l}q_{\mathrm{m}} \\
(\mathrm{mg} / \mathrm{g})\end{array}$ & $b(\mathrm{~L} / \mathrm{mg})$ & $R^{2}$ & & $1 / n$ & $K_{\mathrm{F}}$ & $R^{2}$ \\
\hline $\mathrm{SL}$ & 3.1 & $3.0 \times 10^{-3}$ & 0.9807 & 0.743 & 0.022 & 0.9618 \\
$\mathrm{HC}$ & 5.0 & $3.3 \times 10^{-3}$ & 0.9869 & 0.725 & 0.042 & 0.9695 \\
$\mathrm{CG}$ & 6.0 & $8.3 \times 10^{-3}$ & 0.9916 & 0.577 & 0.176 & 0.9648 \\
\hline
\end{tabular}

Although the correlation coefficients of the Freundlich model were lower than the values calculated with the Langmuir model (Table 3), the experimental data were also used to fit to the Freundlich model, as shown in Fig. 4b. It indicated that both the Langmuir model and the Freundlich model fit the experiment data. The ammonium sorption process onto the three sorbents appeared to involve both a monolayer sorption and a multilayer sorption. The values of $1 / n$ calculated from the Freundlich 
model were all smaller than 1 , indicating a degree of affinity between the ammonium ions and the sorbents.

The effect of $\mathrm{pH}$

The value of the $\mathrm{pH}$ is one of the more critical control parameters in the sorption process, influencing the surface charge of the sorbent, the degree of the ionization and the speciation of the adsorbate (Oğuz 2004). Ranging from 2.0 to 12.0 , the effect of $\mathrm{pH}$ on the ammonium removal by the three materials was observed under similar conditions, with the results given in Fig. 5. With increasing $\mathrm{pH}$, the sorption capacities of the ammonia ion among the sorbents had similar trends, with an initial increase followed by a subsequent decrease. When the $\mathrm{pH}$ values was over 7 , the sorption capacities were higher than the values at low $\mathrm{pH}$, indicating that either neutral or alkaline conditions were favorable for the ammonium removal by the three sorbents. A similar trend had been observed for the sorption of ammonium by zeolites synthesized from fly ash (Wu et al. 2006) and composites of chitosan-g-poly (acrylic acid)/attapulgite (Zheng et al. 2009).

In the solution, the ammonium species may be present in the ionized $\left(\mathrm{NH}_{4}{ }^{+}\right)$and the non-ionized $\left(\mathrm{NH}_{3}\right)$ forms, according to following equation:

$\mathrm{NH}_{4}^{+}+\mathrm{OH}^{-} \Leftrightarrow \mathrm{NH}_{3}+\mathrm{H}_{2} \mathrm{O}$.

When $\mathrm{pH}$ values were below 7 , ammonium exists mainly as $\mathrm{NH}_{4}{ }^{+}$(Maraňón et al. 2006). With a decrease in the $\mathrm{pH}$, an increased competition between the $\mathrm{H}^{+}$in the aqueous solution and the $\mathrm{NH}_{4}{ }^{+}$ions for the exchange sites in the sorbents surface was observed, leading to a low ammonium sorption capacity by the materials. For high $\mathrm{pH}$ values with an abundance of $\mathrm{OH}^{-}$species, the $\mathrm{NH}_{4}^{+}$

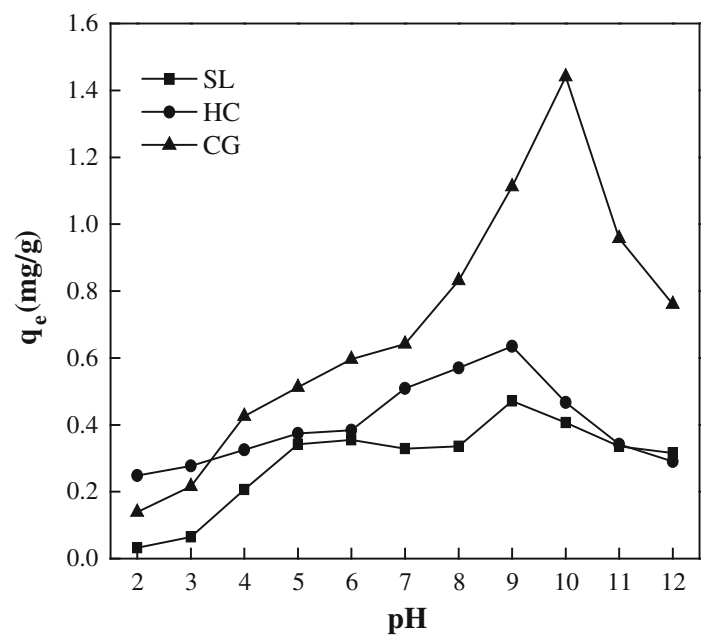

Fig. 5 The effect of $\mathrm{pH}$ on the ammonium adsorption capacity by the adsorbents species were converted into $\mathrm{NH}_{3}$. Although the volatilization of $\mathrm{NH}_{3}$ might have helped remove the ammonium at alkaline $\mathrm{pH}$ values, the low elimination was because the experiment was done in the stopper conical flasks. As observed in the experiments, the partial dissolution of the sorbents occurred at $\mathrm{pH}$ values exceeding 9, which was another reason for the low removal at high $\mathrm{pH}$ (Saltalı et al. 2007).

\section{The effect of temperature}

Figure 6a shows the relationship between the temperature and the ammonium sorption capacity by the SL, HC and $\mathrm{CG}$ samples. The removal of the ammonium onto the three materials increased with increasing temperature, suggesting that the uptake of the ammonium on the materials was controlled by an endothermic process.
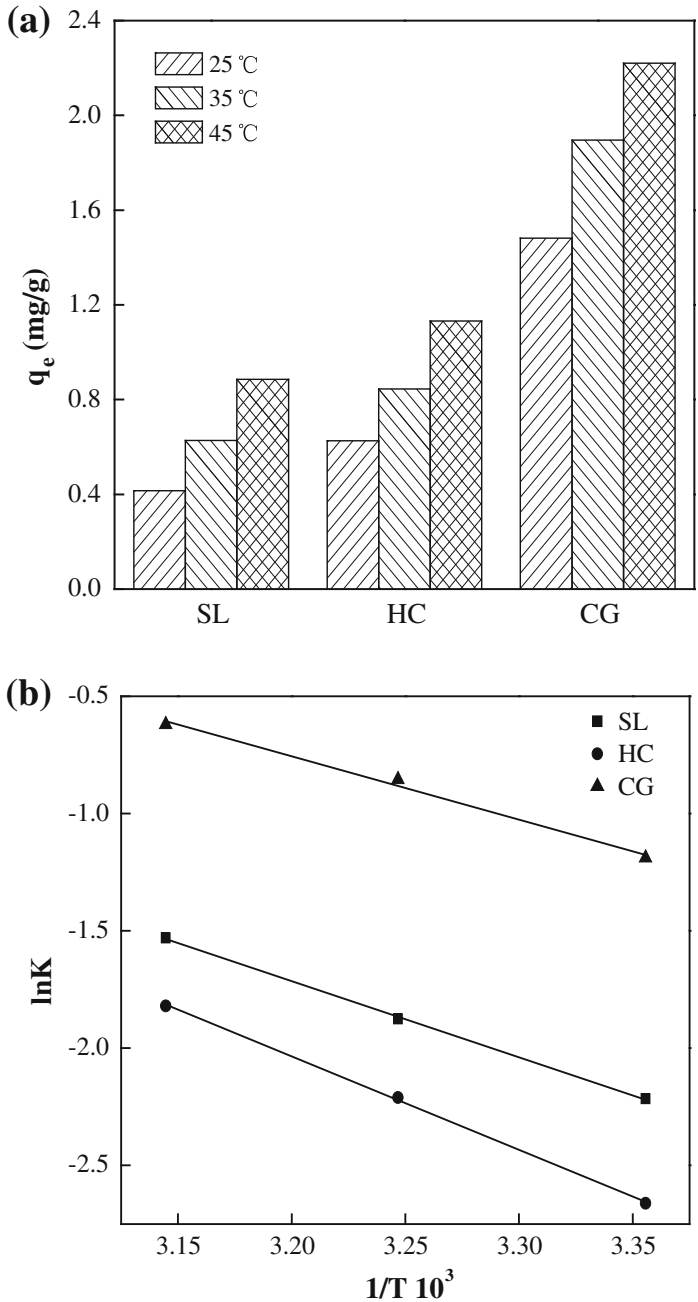

Fig. 6 The effect of temperature on the ammonium adsorption: a the adsorption capacities at different temperatures; $\mathbf{b}$ The plots of $\ln K$ versus $1 / T \times 10^{3}$ 
In practice, the entropy and the Gibbs free energy factors should be taken into consideration to determine the spontaneity of the process. The thermodynamic parameters, such as the enthalpy change $\Delta H$, the entropy change $\Delta S$ and the Gibbs free energy change $\Delta G$, can be calculated using the amount of the ammonium sorption at equilibrium for the different temperatures. According to thermodynamics, the distribution coefficient is related to the enthalpy change $(\Delta H)$ and the entropy change $(\Delta S)$ at constant temperature by the following equation:

$\ln K=\frac{\Delta S}{R}-\frac{\Delta H}{R T}$

$K=\frac{C_{\mathrm{Ae}}}{C_{\mathrm{e}}}$,

where $K$ is the distribution coefficient, $R$ is the gas constant $(\mathrm{kJ} / \mathrm{mol} \cdot \mathrm{K}), C_{\mathrm{Ae}}$ and $C_{\mathrm{e}}$ are the amount adsorbed on solid at equilibrium and the equilibrium concentration $(\mathrm{mg} / \mathrm{L})$, respectively. The free energy change values were calculated from:

$\Delta G=\Delta H-T \Delta S$

The values of $\Delta H$ and $\Delta S$ were calculated from the slope and intercept of the van't Hoff plots of $\ln K$ versus $1 / T$. The values of $\Delta H$ were calculated to be $29.75,25.21$ and $17.91 \mathrm{~kJ} / \mathrm{mol}$ for the SL, HC and CG samples, respectively, as shown in Table 4 and Fig. 6b. The positive values of $\Delta H$ indicated that the ammonium sorption was endothermic process, which was in agreement with the experiment data (Abramian and El-Rassy 2009). The values of $\Delta G$ suggested that these sorption processes were mainly physisorption, as the $\Delta G$ values ranged from 0 to $20 \mathrm{~kJ} / \mathrm{mol}$ (Alkan et al. 2008). The positive values of $\Delta S$ corresponded with a decrease in the randomness at the solid/liquid interface during the adsorption of the ammonium on the three adsorbents.

\section{Conclusion}

The equilibrium time was $2.5 \mathrm{~h}$ for the ammonium sorption by the SL, HC and CG samples, and it was not affected by the initial ammonium concentration. The pseudo second-order

Table 4 Thermodynamic parameters for the ammonium adsorption on the adsorbents

\begin{tabular}{llllll}
\hline Adsorbents & \multicolumn{2}{l}{$\Delta G(\mathrm{~kJ} / \mathrm{mol})$} & & $\Delta H(\mathrm{~kJ} / \mathrm{mol})$ & $\Delta S(\mathrm{~J} / \mathrm{mol} \cdot \mathrm{K})$ \\
\cline { 2 - 4 } & $25^{\circ} \mathrm{C}$ & $35{ }^{\circ} \mathrm{C}$ & $45^{\circ} \mathrm{C}$ & & \\
\hline SL & 6.54 & 5.77 & 4.98 & 29.75 & 77.87 \\
$\mathrm{HC}$ & 5.48 & 4.82 & 4.16 & 25.21 & 66.19 \\
$\mathrm{CG}$ & 2.91 & 2.14 & 1.62 & 17.91 & 51.21 \\
\hline
\end{tabular}

kinetics model provided a better description of the experimental data. The sorption processes fit to both the Langmuir and the Freundlich isotherms model, while the Langmuir model was the better fit. The maximum $q_{\mathrm{m}}$ values were calculated to be $3.1,5.0$ and $6.0 \mathrm{mg} / \mathrm{g}$ for the SL, HC and CG samples, respectively. The ammonium removal was favorable at either neutral or alkaline conditions for all three materials. The thermodynamic parameter $\Delta H$ indicated that all processes were endothermic. In conclusion, these results suggest that coal gangue could be used as a sorbent for the removal of ammonium from wastewater. The low-cost and abundant availability of this material may also contribute to the favorability of coal gangue. It is also concluded that the sorption efficiency might be enhanced by changing the processing conditions, such as the $\mathrm{pH}$ values.

Acknowledgments This work was supported by the National Water Special Project (2009ZX07210-009-02) and the National Science and Technology Support Project (2006BAC10B03).

\section{References}

Abramian L, El-Rassy H (2009) Adsorption kinetics and thermodynamics of azo-dye Orange II onto highly porous titania aerogel. Chem Eng J 150:403-410

Alkan M, Dǒgan M, Turhan Y, Demirbaş Ö, Turan P (2008) Adsorption kinetics and mechanism of maxilon blue $5 \mathrm{G}$ dye on sepiolite from aqueous solutions. Chem Eng J 139:213-223

Bell F, Stacey T (2000) Mining subsidence and its effect on the environment: some differing examples. Environ Geol 40:135-152

Ben Ali MA, Rakib M, Laborie S, Viers P, Durand G (2004) Coupling of bipolar membrane electrodialysis and ammonia stripping for direct treatment of wastewaters containing ammonium nitrate. J Membr Sci 244:89-96

Bulut Y, Aydin H (2006) A kinetics and thermodynamics study of methylene blue adsorption on wheat shells. Desalination 194: 259-267

Coetzee MAA, Van der Merwe MPR, Badenhorst J (2011) Effect of nitrogen loading rates on nitrogen removal by using a biological filter proposed for ventilated improved pit latrines. Int J Environ Sci Tech 8(2):363-372

Dachs J, Eisenreich SJ, Hoff RM (2000) Influence of Eutrophication on air-water exchange, vertical fluxes, and phytoplankton concentrations of persistent organic pollutants. Environ Sci Technol 34:1095-1102

de-Bashan LE, Hernandez JP, Morey T, Bashan Y (2004) Microalgae growth-promoting bacteria as "helper" for microalgae: a novel approach for removing ammonium and phosphorus from municipal wastewater. Water Res 38(2):466-474

Dizadji N, Abootalebi Anaraki N (2011) Adsorption of chromium and copper in aqueous solutions using tea residue. Int J Environ Sci Tech 8(3):631-638

Du Q, Liu S, Cao Z, Wang Y (2005) Ammonia removal from aqueous solution using natural Chinese clinoptilolite. Sep Purif Technol 44:229-234

Gong G, Xie BH, Yang MB (2007) Mechanical properties and fracture behavior of injection and compression molded polypropylene/coal gangue powder composites with and without a polymeric coupling agent. Compos Part A 38:1683-1693 
Gupta S, Babu BV (2009) Removal of toxic metal Cr(VI) from aqueous solutions using sawdust as adsorbent: equilibrium, kinetics and regeneration studies. Chem Eng J 150:352-365

Hameed BH, El-Khaiary MI (2008) Batch removal of malachite green from aqueous solutions by adsorption on oil palm trunk fibre: equilibrium isotherms and kinetic studies. J Hazard Mater $154: 237-244$

Hao CJ (2003) A study adsorption characteristics and mechanism of modified honeycomb-cinder. Ion Exch Adsorpt 19(4):343-350 (in chinese)

Haralambous A, Maliou E, Malamis M (1992) The use of zeolite for ammonium uptake. Water Sci Tech 25:139-145

Ho YS, McKay G (1998) The kinetics of sorption of basic dyes from aqueous solution by Sphagnum moss peat. Can J Chem Eng $76: 822-827$

Ho YS, Mckay G (1999) Pseudo-second order model for sorption processes. Proc. Biochem. 34(5):451-465

Jellali S, Mohammed AW, Anane M, Riahi K, Jedidi N (2011) Biosorption characteristics of ammonium from aqueous solutions onto Posidonia oceanica (L.) fibers. Desalination 270:40-49

Joo HS, Hirai M, Shoda M (2007) Improvement in ammonium removal efficiency in wastewater treatment by mixed culture of Alcaligenes faecalis No. 4 and L1. Biosci. Bioeng. 103:66-73

Karadag D, Koc Y, Turan M, Armagan B (2006) Removal of ammonium ion from aqueous solution using natural Turkish clinoptilolite. J Hazard Mater 136:604-609

Kavitha D, Namasivayam C (2007) Experimental and kinetic studies on methylene blue adsorption by coir pith carbon. Bioresour Technol 98:14-21

Kurama H, Karagüzel C, Mergan T, Çelik MS (2010) Ammonium removal from aqueous solutions by dissolved air flotation in the presence of zeolite carrier. Desalination 253:147-152

Lee JC, Wang JY, Xu ZF (2010) Studies on the phosphorus sorption capacity of substrates used in constructed wetlands. Bioinform Biomed Eng (ICBBE)

Lei LC, Li XJ, Zhang XW (2008) Ammonium removal from aqueous solutions using microwave-treated natural Chinese zeolite. Sep Purif Technol 58:359-366

Li DX, Song XY, Gong CC, Pan ZH (2006) Research on cementitious behavior and mechanism of pozzolanic cement with coal gangue. Cem Concr Res 36:1752-1759

Liu ZF, Lee C (2007) The role of organic matter in the sorption capacity of marine sediments. Mar Chem 105:240-257

Maraňón E, Ulmanu M, Fernándeza Y, Anger I, Castrillón L (2006) Removal of ammonium from aqueous solutions with volcanic tuff. J Hazard Mater B 137:1402-1409

McKinnon E (2002) The environmental effects of mining waste disposal at Lihir Gold Mine, Papua New Guinea. J Rural Remote Environ Health 1:40-50

McVeigh RJ (1999) The enhancement of ammonium ion removal onto columns of clinoptilolite in the presence of nitrifying bacteria. $\mathrm{PhD}$ research dissertation, Department of Chemical Engineering, The Queens University of Belfast
Nehrenheim E, Gustafsson JP (2008) Kinetic sorption modelling of $\mathrm{Cu}, \mathrm{Ni}, \mathrm{Zn}, \mathrm{Pb}$ and $\mathrm{Cr}$ ions to pine bark and blast furnace slag by using batch experiments. Bioresour Technol 99:1571-1577

Oğuz E (2004) Removal of phosphate from aqueous solution with blast furnace slag. J. Hazard. Mater. B 114:131-137

Onundi YB, Mamun AA, Al Khatib MF, Ahmed YM (2010) Adsorption of copper, nickel and lead ions from synthetic semiconductor industrial wastewater by palm shell activated carbon. Int J Environ Sci Technol 7(4):751-758

Qin QY, Jia CZ, Zhou XL (2007) Research on absorption treatment of wastewater containing chromium by active coal Gangue. Ind Saf Environ Prot 33(6):23-25

Rožić M, Cerjan-Stefanović Š, Kurajica S, Vančina V, Hodzžić E (2000) Ammoniacal nitrogen removal from water by treatment with clays and zeolites. Water Res 34(14):3675-3681

Saltalı K, Sarı A, Aydın M (2007) Removal of ammonium ion from aqueous solution by natural Turkish (Yıldizeli) zeolite for environmental quality. J Hazard Mater 141:258-263

Shi L, Niu DJ, Jin L (2005) Comprehensive Utilization of Coal Shale. Coal Chem. Ind. 4:15-18

Sondergaard M, Jeppesen E (2007) Anthropogenic impacts on lake and stream ecosystems, and approaches to restoration. J Appl Ecol 44:1089-1094

Sprynskyy M, Lebedynets M, Zbytniewski R, Namiésnik J, Buszewski B (2005) Ammonium removal from aqueous solution by natural zeolite, Transcarpathian mordenite, kinetics, equilibrium and column tests. Sep Purif Technol 46:155-160

Uğurlu M, Karaoğlu MH (2011) Adsorption of ammonium from an aqueous solution by fly ash and sepiolite: isotherm, kinetic and thermodynamic analysis. Micropor. Mesopor. Mater. 139:173-178

Wang XM, Zhao B, Zhang CS, Zhang QL (2009) Paste-like selfflowing transportation backfilling technology based on coal gangue. Mini. Sci. Technol. 19:137-143

Wang GZ, Wu JF, Wang XL (2010) Experiment research on modified coal reject applied to remove ammonia nitrogen in waste water. Coal Eng. 6:87-88

Weber WJ, Morris JC (1963) Kinetics of adsorption on carbon from solution. J. Sanit. Eng. ASCE 89:31-42

Wu D, Zhang B, Li C, Zhang Z, Kong H (2006) Simultaneous removal of ammonium and phosphate by zeolite synthesized from fly ash as influenced by salt treatment. J. Colloid Interf. Sci. 304:300-306

Xi YF, Mallavarapu M, Naidu R (2010) Preparation, characterization of surfactants modified clay minerals and nitrate adsorption. Appl Clay Sci 48:92-96

Xue YJ, Hou HB, Zhu SJ (2009) Adsorption removal of reactive dyes from aqueous solution by modified basic oxygen furnace slag: isotherm and kinetic study. Chem Eng J 147:272-279

Yang M, Uesugi K, Myoga H (2007) Ammonia removal in bubble column by ozonation in the presence of bromide. Water Res 33:1911-1917

Zheng Y, Zhang JP, Wang AQ (2009) Fast removal of ammonium nitrogen from aqueous solution using chitosan-g-poly (acrylic acid)/attapulgite composite. Chem Eng J 155:215-222 